\title{
INTERFERÊNCIA DE MUCUNA-PRETA EM CULTIVARES DE AMENDOIM
}

Ana Julia Borges Lima'; Willians César Carrega ${ }^{2}$; Pablo Nascimento de Oliveira França ${ }^{3}$; Bruno Saravali Silveira ${ }^{4}$; Jose Davi Phelipe ${ }^{5}$; Pedro Luis da Costa Aguiar Alves ${ }^{6}$

${ }^{1}$ Graduando em Agronomia, FCAV/UNESP, Jaboticabal, SP, willianscesar@hotmail.com; ${ }^{2}$ Doutor em Agronomia (Produção Vegetal), FCAV/UNESP, Jaboticabal, SP; ${ }^{3}$ Mestrando em Agronomia (Ciência do Solo), FCAV/UNESP, Jaboticabal, SP; ${ }^{4}$ Graduando em Agronomia, FCAV/UNESP, Jaboticabal, SP; ${ }^{5}$ Graduando em Agronomia, FCAV/UNESP, Jaboticabal, SP; ${ }^{6}$ Docente da FCAV/UNESP, Jaboticabal, SP.

RESUMO: A interferência causada pelas plantas daninhas na cultura do amendoim pode causar grandes perdas no rendimento e a busca por cultivares com maior potencial competitivo é de fundamental importância para minimizar esse efeito. Por isso, o objetivo deste trabalho foi avaliar a interferência da mucuna-preta (Mucuna aterrima), uma infestante recente, em cinco cultivares de amendoim rasteiro. Realizou-se um experimento, em delineamento casualizado, com três repetições, comparando a convivência de cinco cultivares de amendoim com a mucuna-preta durante todo o ciclo do amendoim. Verificou-se que a massa seca das plantas de amendoim foi afetada pela interferência da mucuna-preta e houve reduções na produtividade que variaram de $73 \%$ a $90 \%$, sendo que o rendimento das cultivares IAC 503, IAC 505, IAC OL3, IAC OL4 e IAC OL5 sofreu redução quando em convivência com a mucuna-preta durante longo período.

Palavras-chave: Arachis hypogaea L., competição, Mucuna aterrima, planta daninha, produtividade.

\section{INTRODUÇÃO}

A produção mundial de amendoim na última safra (2017/18) foi estimada em 44 milhões de toneladas (USDA, 2018). Em âmbito nacional, a produção de amendoim foi de aproximadamente 513 mil toneladas, com o Estado de São Paulo como o principal produtor, responsável por $90 \%$ do total produzido (CONAB, 2018).

Dente os fatores que podem afetar o potencial produtivo dessa cultura, a interferência decorrente da competição com as plantas daninhas pode causar perdas que variam entre 31 e $92 \%$ (AGOSTINHO et al., 2006; YAMAUTI et al., 2010), dependendo da cultivar, do espaçamento, da densidade e do período de convivência, que podem ser modificados pelas condições climáticas e pelas características culturais utilizadas (PITELLI, 1985).

Entre as plantas daninhas, a mucuna-preta (Mucuna aterrima) é uma espécie que foi introduzida no Brasil como um adubo orgânico, visando melhorar a qualidade dos solos em áreas canavieiras em reforma. Entretanto, pelo manejo inadequado e devido a dormência de suas sementes, essa espécie se tornou uma planta daninha (CORREIA, 2011; SILVA et al., 2013; DE SOUZA et al., 
2015) e têm causado grandes prejuízos nas áreas de produção de cana-de-açúcar e, consequentemente, em áreas de amendoim, que comumente é semeado em áreas de renovação de canaviais. Bressanin et al. (2016), observaram em uma área de cana-de-açúcar que 98\% da comunidade de plantas daninhas foi composta por mucuna-preta.

Diante do exposto, a busca por cultivares com maior potencial competitivo com as plantas daninhas, entre elas, a mucuna-preta é de fundamental importância. Por isso, o objetivo deste trabalho foi avaliar a interferência da mucuna-preta em cinco cultivares de amendoim, visando selecionar os cultivares mais competitivos e, também, avaliar o impacto dessa planta daninha no potencial produtivo do amendoim.

\section{MATERIAL E MÉTODOS}

O experimento foi conduzido no Laboratório de Plantas Daninhas (LAPDA), localizado na Universidade Estadual Paulista “Júlio de Mesquita Filho”, Câmpus de Jaboticabal, São Paulo.

O delineamento foi em blocos casualizados, tendo como tratamentos cinco cultivares (IAC 503, IAC 505, IAC OL3, IAC OL4 e IAC OL5) submetidos ou não a convivência com a mucuna-preta durante todo o ciclo do amendoim, em 3 repetições.

Realizou-se a semeadura das cinco cultivares em canteiros cujas dimensões foram de $0,50 \mathrm{~m}$ de largura por 0,50 m de comprimento, preenchidos com Latossolo Vermelho Escuro (EMBRAPA, 2013). Em cada canteiro foram depositadas 20 sementes/metro, previamente tratadas com inseticida tiametoxan (Cruiser ${ }^{\circledR}-200 \mathrm{~mL}$ do p.c. $/ 100 \mathrm{~kg}$ de sementes) e fungicida carboxina + tiram (Vitavax ${ }^{\circledR}-$ Thiram $200 \mathrm{SC}-350 \mathrm{~mL}$ do p.c./100 kg de sementes). Após a emergência das plantas, realizou-se o desbaste, deixando-se 12 plantas por caixa. No momento da semeadura das cultivares, nos tratamentos submetidos à interferência, realizou-se a semeadura da mucuna-preta, depositando-se 10 sementes e, após a emergência, manteve-se cinco plantas por canteiro.

A planta daninha foi deixada do início ao final do ciclo de cada cultivar e, ao término do período experimental, foi determinada a massa seca da parte aérea da planta daninha e do amendoim, após secagem em estufa de circulação forçada de ar, a $70{ }^{\circ} \mathrm{C}$, até atingirem massa constante. Neste momento, também foi determinado o rendimento por parcela de cada cultivar de amendoim.

Os resultados obtidos foram submetidos a análise de variância pelo teste $\mathrm{F}$ e as médias comparadas pelo teste de Tukey $(\mathrm{p}>0,05)$, utilizando o software Agroestat (Barbosa; Maldonado Junior, 2015).

\section{RESULTADOS E DISCUSSÃO}

As plantas de mucuna-preta acumularam, em média, $2,179 \mathrm{~kg}^{-1}$ de massa seca por parcela ao longo do ciclo do amendoim (Figura 1). Essa quantidade de massa interferiu diretamente na cultura, causando reduções no crescimento e desenvolvimento das plantas de amendoim e, consequentemente, perdas na produtividade (Figuras 2). 


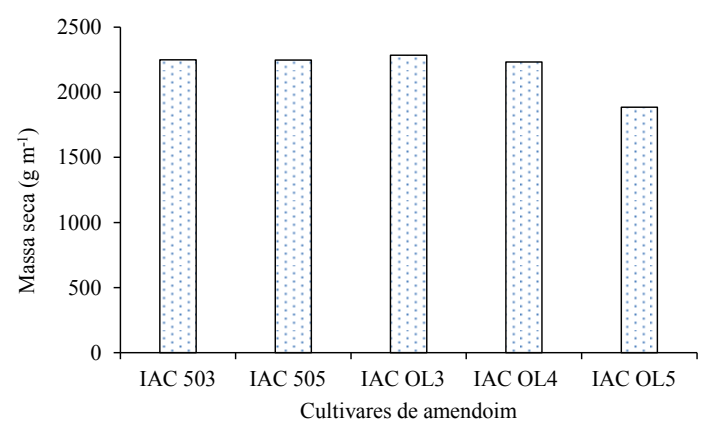

Figura 1. Massa seca de plantas de mucuna-preta acumulada ao término do período experimental.

Verificou-se que a massa seca das cinco cultivares de amendoim convivendo com a mucunapreta foi reduzida significativamente, quando comparada com os tratamentos sem a planta daninha (Figura 2A). A porcentagem de redução variou de $59 \%$ a $81 \%$, sendo a cultivar IAC OL3 a que mais suportou a convivência com a mucuna-preta, sofrendo redução de $59 \%$, enquanto as cultivares IAC OL4, IAC 503, IAC OL5 e IAC 505 sofreram reduções de 73\%, 73\%, 80\% e 81\%, respectivamente, quando em convivência com a planta daninha (Figura 2A). Ressalta-se que mesmo a cultivar IAC OL3 apresentando maior potencial competitivo, com menor redução na massa seca, houve reduções significativas no crescimento e desenvolvimento das cultivares, e isso é um dos principais fatores que levou às perdas no rendimento do amendoim, como observado na Figura 2B.
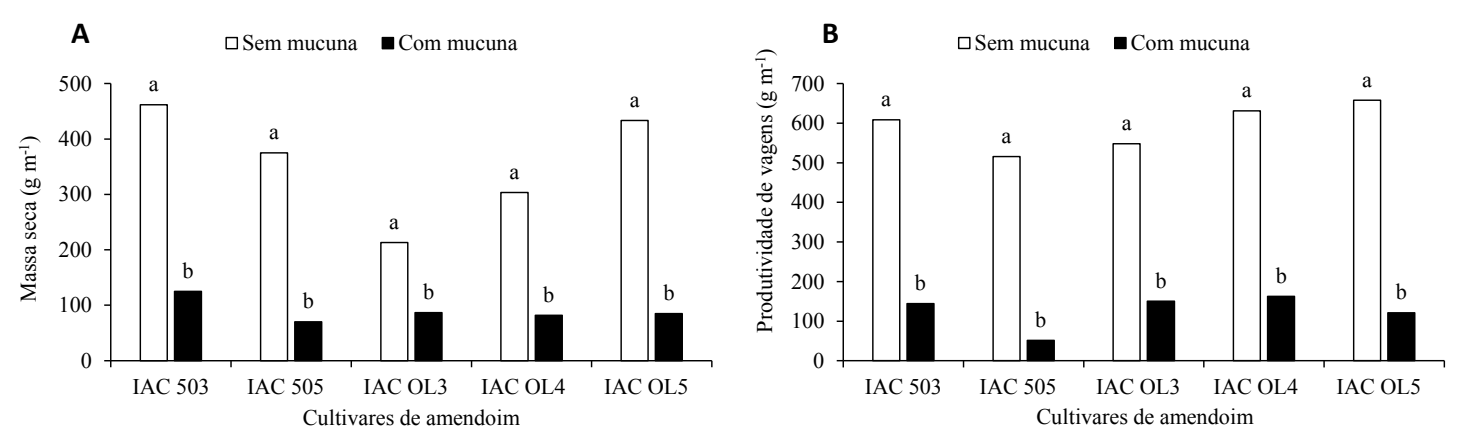

Figura 2. Massa seca $\left(\mathrm{g} \mathrm{m}^{-1}\right)$ e Produtividade $\left(\mathrm{g} \mathrm{m}^{-1}\right)$ de plantas de cinco cultivares de amendoim rasteiro submetidos a interferência ou não da mucuna-preta.

Analisando a produtividade de vagens $\left(\mathrm{g} \mathrm{m}^{-1}\right)$, observou-se redução significativa para todas as cultivares avaliadas. A interferência da mucuna-preta na cultura causou reduções que variaram de 73\% a $90 \%$ no rendimento das cultivares de amendoim (Figura 2B). Essa redução no potencial produtivo do amendoim está diretamente relacionada com a redução na massa vegetativa da planta. Korav et al. (2018) mencionam que geralmente as plantas daninhas competem durante o crescimento da cultura, utilizando mais eficientemente os recursos do meio e ressaltam que após determinado período as plantas daninhas são suprimidas pela cultura devido ao efeito sufocante. Contudo, para espécies de 
16 e 17 de agosto de 2018, centro de convenções da FCAV/UNESP - Câmpus de Jaboticabal, SP

Mucuna spp. e Ipomoea spp. em condições ideais de luz, água e nutrientes, o crescimento dessas espécies daninhas é mais rápido que do amendoim, e isso faz com que as plantas daninhas sejam mais agressivas, entrelaçando-se na cultura e causando sombreamento do amendoim, impedindo a absorção de energia luminosa pelas plantas. Bressanin et al. (2016) também verificaram que a interferência em decorrência do sombreamento causado pela mucuna-preta em cana-de-açúcar promoveu reduções de $50 \%$, afetando negativamente a qualidade do produto colhido.

A menor taxa de interceptação da radiação, por meio do sombreamento, promove redução das atividades fotossintéticas essenciais para o crescimento, desenvolvimento e rendimento da cultura. No presente estudo, verificou-se que a interferência causada pela convivência com essa planta daninha reduziu $73 \%, 74 \%, 76 \%, 82 \%$ e $90 \%$ da produtividade das cultivares, IAC OL3, IAC OL4, IAC 503 , IAC OL5 e IAC 505, respectivamente. (Figura 2B).

\section{CONCLUSÃO}

A produtividade das cultivares IAC 503, IAC 505, IAC OL3, IAC OL4 e IAC OL5 sofreu interferência quando em convivência com a mucuna-preta. Por isso, para minimizar os impactos da interferência dessa planta daninha, recomenda-se a adoção de estratégias de controle, utilizando o manejo integrado de plantas daninhas.

\section{REFERÊNCIAS BIBLIOGRÁFICAS}

Agostinho, F. H.; GRAVENA, R.; AlVES, P. L. C. A.; SAlgAdO, T. P.; MATTOS, E. D. The effect of cultivar on critical periods of weed control in peanuts. Peanut Science, v.33, n.1, p.29-35, 2006.

BARBOSA, J. C.; MALDONADO JUNIOR, W. 2015. AgroEstat. Sistema para análises Estatísticas de ensaios agronômicos. Jaboticabal: FCAV/UNESP. 396p.

BRESSANIN, F. N.; JAYME NETO, N.; NEPOMUCENO, M. P.; ALVES, P. L. D. C. A.; CARREGA, W. C. Interference periods of velvet bean in sugarcane. Ciência Rural, v.46, n.8, p.13291337, 2016.

CONAB. Companhia Nacional de Abastecimento (2018). Acompanhamento da Safra Brasileira, Grãos. Disponível: http://www.conab.gov.br. Acesso: 17 de abril de 2018.

CORREIA, N. M. Eficácia do mesotrione aplicado isolado e em mistura para o controle de corda-deviola e de mucuna-preta em cana-soca. Álcoolbras, v.3, n.133, p.46-51, 2011.

DE SOUZA, G. C.; TIMOSSI, P. C.; DA COSTA NETTO, A. P.; RODRIGUES, M. J.; FARIA FILHO, L. A. Germinação de sementes de mucuna-preta submetidas a diferentes períodos de armazenamento. Revista Brasileira de Energia Renováveis, v.4, n.1, p.72-83, 2015.

EMBRAPA, Empresa Brasileira de Pesquisa Agropecuária. Sistema brasileiro de classificação de solos. 3.ed. Brasília, 2013. 353p. 
KORAV, S.; RAM, V.; RAY, L. I.; KRISHNAPPA, R.; SINGH, N. J.; PREMARADHYA, N. Weed Pressure on Growth and Yield of Groundnut (Arachis hypogaea L.) in Meghalaya, India. International Journal of Current Microbiology and Applied Sciences, v.7, n.3, p.2852-2858, 2018.

PITELLI, R. A. Interferência de plantas daninhas em culturas agrícolas. Informe Agropecuário, v.11, n.29, p.16-27, 1985.

SILVA, G. B. F.; AZANIA, C. A. M.; NOVO, M. C. S. S.; WUTKE, E. B.; ZERA, F. S.; AZANIA, A. A. P. M. Overcoming depth sowing and mulch density in Mucuna aterrima, Mucuna deeringiana and Mucuna cinerea. Planta Daninha, v.31, n.2, p.313-317, 2013.

USDA. United States Departamento of Agriculture. World Agricultural Production. Foreign Agricultural Service (Circular Series WAP 01-17), Abril, 2018. Disponível: https://apps.fas.usda.gov/psdonline/circulars/production.pdf. Acesso: 17 de abril de 2018.

YAMAUTI, M. S.; ALVES, P. L. C. A.; NEPOMUCENO, M.; MARTINS, J. V. F. Adubação e o período anterior à interferência das plantas daninhas na cultura do amendoim. Planta Daninha, v.28, p.1031-1039, 2010. 